\title{
Editorial
}

\section{Developments in the Theory and Practice of Cognitive and Behavioural Therapies}

In 1993 Behavioural and Cognitive Psychotherapy published a supplement edited by Ann Hackmann with the title "Behavioural and Cognitive Psychotherapies: Past History, Current Applications and Future Registration Issues". This was the journal's first ever supplement and it provided an overview of the state of behavioural and cognitive psychotherapies at that time. It was intended to provide a context for discussions concerning the future of the field, and as Paul Salkovskis said in his editorial, "[the supplement]... will be an important reference source for years to come."

The 1993 supplement was requested by the National Executive of the British Association for Behavioural and Cognitive Psychotherapies (BABCP). At that time the Association was considering registration criteria for its members who wished to register with the United Kingdom Council for Psychotherapy. The supplement was intended to set out the characteristic features of the behavioural and cognitive psychotherapies to help with drawing up criteria for registration. As well as considering the nature and origins of the behavioural and cognitive psychotherapies, the supplement outlined the main treatment techniques in use at that time. These were listed as operant conditioning, exposure therapy, arousal reduction interventions, skills training and, finally, cognitive techniques, including cognitive therapy! The chapter outlining "current applications" looks familiar in terms of its description of the building evidence for cognitive behavioural interventions for depression, anxiety states, eating disorders etc. However, applications with older people, people with learning disabilities, children and psychosis were in the very early stages of development and the focus remained on behaviour modification and behavioural therapy. There were also sections on applications in social work and educational settings, which have received less attention in recent years.

Following some initial proposals from Paul Gilbert and Mary Welford, the BABCP Board decided it was time to update the 1993 supplement and some 15 years on it asked us to bring together a collection of papers that would bring readers (academics, clinicians and trainers) up-to-date with theoretical, conceptual, and practice developments in the cognitive and behavioural therapies field.

To achieve this we encouraged contributions on new and emerging areas such as metacognition, mindfulness, ACT, and stepped care and self-help. We also invited papers on developments in established areas of CBT practice e.g. anxiety, psychosis, mood and eating disorders. In addition, papers on innovative applications of these approaches to particular client groups including children and families, older people and people with intellectual disabilities were sought, along with considerations of process issues such as formulation, therapeutic relationships and supervision. Due to space limitations this cannot be an exhaustive collection, and some important areas of established and emerging practice are not covered (e.g. physical health care settings, personality disorders, imagery). 
Each of the 15 papers in this special issue attempts to provide a digest of developments in the particular area it covers. Where possible, and appropriate, the papers provide some historical context and cover recent developments in theory, research and practice, and future directions. They are meant to reflect innovations in theory, research and practice, rather than give a straightforward review of research in their particular area or report on data from empirical studies. Whilst set in a different context and a generation on, we hope that this eclectic set of papers goes at least someway to updating the excellent overview provided by Ann Hackmann and her colleagues in 1993, and will be of interest to the Association's membership and a wider readership of those interested in the development and application of cognitive and behavioural psychotherapies.

We would like to thank Paul Salkovskis and Manuela Herrera in the journal editorial office, Jamie Hutchins, Sue Perkins and Carole Hughes at Cambridge University Press and, not least, the manuscript reviewers for their support with this project.

John L. Taylor and Craig Steel

Guest Editors

October 2008

\section{Reference}

Hackmann, A. (1993). Behavioural and cognitive psychotherapies: past history, current applications and future registration issues [Supplement 1]. Behavioural and Cognitive Psychotherapy, 21, 1-75. 